\title{
Assessing horizontal equity in health care utilization in Iran: a decomposition analysis
}



Farideh Mostafavi ${ }^{1}$, Bakhtiar Piroozi ${ }^{1}$, Paola Mosquera ${ }^{2}$, Reza Majdzadeh ${ }^{3}$ and Ghobad Moradi ${ }^{1,4^{*}}$ (D)

\begin{abstract}
Background: Despite the goal of horizontal equity in Iran, little is known about it. This study aimed i) to assess socioeconomic inequality and horizontal inequity in the healthcare utilization; and ii) to explore the contribution of need and non-need variables to the observed inequalities.

Methods: This study used national cross sectional dataset from Utilization of Health Services survey in 2015. Concentration Index (C), Concentration Curve (CC) and Horizontal Inequity index (HI) were calculated to measure inequality in inpatient and outpatient health care utilization. Decomposition analysis was used to determine the contribution of need and non-need factors to the observed inequalities.
\end{abstract}

Result: Results showed the pro-poor inpatient services in both rural $(C=-0.079)$ and non-rural areas $(C=-0.096)$ and the pro-rich outpatient services in both rural $(C=0.038)$ and non-rural $(C=0.007)$. After controlling for need factors, $\mathrm{HI}$ was positive and significant for outpatient services in rural $(H \mathrm{H}=0.039)$ and non-rural $(H \mathrm{I}=0.008)$, indicating that for given need, the better off especially in rural make greater use of outpatient services. The HI was pro-poor for inpatient services in both rural $(H \mathrm{H}=-0.068)$ and non-rural $(H \mathrm{H}=-0.090)$, was significant only in nonrural area. Non-need factors were the most important contributors to explain inequalities in the decomposition analysis.

Conclusion: Disentangle the different contribution of determinants, as well as greater $\mathrm{HI}$ in rural areas for outpatient and in non-rural areas for inpatient services, provide helpful information for decision makers to re-design policy and re-distribute resource allocation in order to reduce the socioeconomic gradient in health care utilization.

Keywords: Health inequalities, SOCIO-ECONOMIC, SOCIAL INEQUALITIES, HEALTH SERVICES

\section{Background}

Equitable access and utilization of health services is one of the goals, tasks and challenges of governments [1]. Universal health coverage (UHC) is an important step toward achieving equity in the utilization of health services by all people $[2,3]$. Typically, in high-income countries poorer individuals utilize more health care services due to need factors (i.e. lower health status).

\footnotetext{
* Correspondence: moradi_gh@yahoo.com

'Social Determinants of Health Research Center, Kurdistan University of Medical Sciences, Sanandaj, Iran

${ }^{4}$ Department of Epidemiology and Biostatistics, Kurdistan University of Medical Sciences, Pasdaran Ave, Sanandaj, Iran

Full list of author information is available at the end of the article
}

Conversely in low-income countries, poorer individuals are less likely to use services due to non-need factors (i.e. low income and lack of health insurance) and despite their greater need [4]. The principle of Universal health coverage (UHC) states that individuals with equal needs should utilize equal healthcare services $[5,6]$. Therefore, as poorer individuals often face lower health status and greater need it is expected that they utilize more health services. but also to support the fullfilment of the UHC Monitoring horizontal equity is deemed necesary not only to provide a comprehensive picture of equity in health care $[7,8]$.

Iran, like many other countries, has set UHC and health equity as some of its main goals [9]. One of the

C The Author(s). 2020 Open Access This article is licensed under a Creative Commons Attribution 4.0 International License, which permits use, sharing, adaptation, distribution and reproduction in any medium or format, as long as you give appropriate credit to the original author(s) and the source, provide a link to the Creative Commons licence, and indicate if changes were made. The images or other third party material in this article are included in the article's Creative Commons licence, unless indicated otherwise in a credit line to the material. If material is not included in the article's Creative Commons licence and your intended use is not permitted by statutory regulation or exceeds the permitted use, you will need to obtain permission directly from the copyright holder. To view a copy of this licence, visit http://creativecommons.org/licenses/by/4.0/. The Creative Commons Public Domain Dedication waiver (http://creativecommons.org/publicdomain/zero/1.0/) applies to the data made available in this article, unless otherwise stated in a credit line to the data. 
first effort was the establishment of a public health care (PHC) network fully financed by the government in 1985 [10-12]. In 1989 The Social Security Act was enacted and the Social Security Organization was appointed as the institution responsible to implement and provide health care services for workers and persons covered by the Labor and Social Security Law. In addition, the Imam Khomeini Relief Foundation, was created by the government as a subsidy fund to cover inpatient services for poor and low-income individuals [10]. In 2005 the Family Physician Program and a Universal Health Insurance scheme were implemented with full financial support for rural areas, and partial financial support for urban residents [12, 13]. Lately, in 2014 the implementation of the Health Transformation Plan was an important step taken by the government (more focus on inpatient services in public sector) to achieve public health coverage through reducing the amount of out of pocket payment [14-16].

Little is known about equality in health care utilization in Iran, and equity was not studied nationally or methodologically. Previous studies in Iran have shown prorich inequalities in healthcare utilization, in which Sex, place of residence and health insurance coverage have been reported as the main predictors of observed inequalities [17-19]. On the same data of this study, a study using logistic regression models to analyze association between social variables with the self-reported need and usage of services in people who reported need; poor people reported more both of outpatient and inpatient needs than rich people, as well as usage of inpatient services was more in rich people and was not significant for outpatient services [20].

Equity in health care in Iran may therefore require being re-assessed and permanently monitored. To contribute and update the knowledge about horizontal equity in health care utilization in Iran, the present study aimed: i) to assess socioeconomic inequality and horizontal inequity in the utilization of health services; and ii) to explore the contribution of need and non-need variables to the observed inequalities.

\section{Methods}

\section{Study design and participants}

This study used national cross sectional dataset from Utilization of Health Services (UHS) survey in 2015. UHS was conducted by National Institute of Health Research under the supervision of the Statistical Centre of Iran and in coordination with the relevant departments in the Ministry of Health and Medical Education.

The target population of this study was a set of ordinary resident households (ordinary households are made up of several people who live together in a fixed residence, have the same expenditure and usually eat together) and group households, i.e. a group of people who all or most of them, due to their special circumstances, mainly have a common feature, have chosen a joint residence for their living and jointly manage the affairs of life in that residence. These were selected according to the latest general population and housing census of Iran in 2011. Institutional households such as student dormitories, barracks, and prisons were not included in the study.

The samples were selected using three-stage stratified probability sampling method; i) each province was classified into non-rural/rural geographic segment. ii) the non-rural areas were classified into two categories of "central city/non-central city" segment. iii) 20 households were selected from each segment using simple random sampling method. Which 10 households were selected as the main sample and 10 households were selected as the alternative sample.

The total number of segments in the whole country $(\mathrm{m})$ is obtained by dividing the number of ordinary and group households by 10, and sample areas obtained from following formula:

$$
\begin{aligned}
m_{t h} & =\frac{\sqrt{N_{t h}}}{\sum \sqrt{N_{t h}}} \times m \quad t=1,2,3, \ldots, 31, h \\
& =1,2,3
\end{aligned}
$$

$\mathrm{m}_{\mathrm{th}}$ is the number of sample areas in the $\mathrm{h}^{\text {th }}$ class of $\mathrm{t}^{\text {th }}$ province. $\mathrm{N}_{\text {th }}$ is the number of ordinary resident households living in the $\mathrm{h}^{\text {th }}$ class/category of the $\mathrm{t}^{\text {th }}$ provinces (from 31 provinces) based on the general census of population and housing in 2011.

A total of 22,470 households were enrolled in this study ( $N=81,137$ invited, $N=78,378$ participated), and the response rate was $96.6 \%$.

For the present study, resulting in a sample size of 12 , 944 individuals had been received health care from health care facility in the last 2 weeks, and 5404 individuals had been admitted to a hospital in the last year. Data were collected using a questionnaire via interviews. This study was conducted according to the guidelines laid down in the Declaration of Helsinki.

\section{Variable definition}

Outcome variables were measured by health care utilization in inpatient and outpatient care, derived from the questions: "Have you been admitted to a hospital in the last year?" and "Have you received health care from a health care facility in the last two weeks?" respectively. Both variable coded as yes $=1$ or no $=0$.

To calculate the socioeconomic status variable, we used the data on a number of assets collected as part of the UHS survey. Using principal component analysis (PCA), an asset index was calculated for each of the 
subjects. We divided individuals based on "rank" instead of "weight" for the quintiles included in the decomposition. The index ranks people from the poorest to the richest, by classifying them into five quintiles: very poor, poor, moderate, rich, and very rich [21, 22].

Need factors included demographic variables (age and sex) and a health variable (self-reported health), used as proxies of need [4]. Age was categorized into three groups, less than 30 years, $30-59$ and 60 years and older. Sex was defined as male/female. Self-reported health status variable was dichotomized into two groups good and poor. The information for this variable was derived from the question: "you had Have any major illness or suffered from any disability for at least the past year?" (Yes/ No). Having either illness or disability was considered poor health and having no illness or disability was measured as good health status.

Non-need factors included socioeconomic status variables, education, basic and supplementary insurance, marital status, and occupation. Education was categorized into three groups: uneducated \& elementary, middle \& high school and college and above. Basic and supplementary insurance variables were both coded as yes $=1$ or no $=0$. Marital status was categorized into married or single and occupation or having job was defined as yes/no.

\section{Statistical analysis}

First Concentration Index (C), Concentration Curve (CC) and Horizontal Inequity index (HI) were calculated to measure inequality in health care utilization. To form $\mathrm{CC}$, individuals are sorted according to their socioeconomic status, then the cumulative percentage of population is plotted against the cumulative percentage of health variable. CC above (below) the line of equality indicate health variable is concentrated among poor (rich) individuals. $\mathrm{C}$ values range from +1 to -1 . Positive (negative) value indicates the health variable is concentrated among rich (poor) individuals, and $\mathrm{C}$ equals zero means there is no inequality. To calculate the $\mathrm{C}$, The Kakwani method was used by the following eq. (22): (Eq. 2)

$$
C=\frac{2}{\mu} \operatorname{cov}\left(y_{i}, R_{i}\right)
$$

Where $\mathrm{C}$ is concentration index, Cov is the Covariance, $y_{i}$ is the health variable, $R_{i}$ is the $i^{\text {th }}$ individual's fractional rank in the socioeconomic distribution and $\mu$ is the health variable mean. Wagstaff correction [23] to the $C$ was used because of binary outcome variables.

Decomposition analysis was used to determine the contribution of need and non-need factors to the observed inequalitc we used the linear approximation of a probit model to estimate partial effects [22] (Eq. 3).

$$
y_{i}=\alpha^{m}+\sum_{j} \beta_{j}^{m} x_{j i}+\sum_{k} \gamma_{k}^{m} Z_{k_{i}}+\varepsilon_{i}
$$

The decomposition of the concentration index for $y_{i}$, can thus be expressed as the following formula (Eq. 4):

$$
C=\sum\left(\frac{\beta_{j}^{m} \bar{x}_{j}}{\mu}\right) C_{j}+\sum\left(\frac{\gamma_{k}^{m} \bar{Z}_{k}}{\mu}\right) C_{k}+\frac{G C_{\varepsilon}}{\mu}
$$

where, $\mu$ is the mean $y_{i}$ (health care utilization), $C_{j}$ and $C_{k}$ are the concentration indices for $X_{j}$ (need factors) and $Z_{k}$ (non-need factors), $\beta_{j}^{m}$ and $\gamma_{k}^{m}$ are the partial effects $\left(\mathrm{d}_{\mathrm{y}} / \mathrm{dx}_{\mathrm{j}}, \mathrm{d}_{\mathrm{y}} / \mathrm{dz}_{\mathrm{k}}\right)$ for $\mathrm{x}$ and $\mathrm{z}, \overline{\mathrm{x}}_{\mathrm{j}}$ and $\bar{Z}_{\mathrm{k}}$ are the mean level of $X_{j}$ and $Z k,\left(\frac{\beta_{j}^{m} \bar{x}_{j}}{\mu}\right) C_{j}$ and $\left(\frac{\beta_{j}^{m} \bar{x}_{j}}{\mu}\right) C_{j}$ are the contributions of need variables $(\mathrm{j})$ and non-need variables $(\mathrm{k})$, and $\frac{G C_{\varepsilon}}{\mu}$ is the generalized concentration index for the remaining error $[22,24]$.

Finally, the horizontal index was obtained from the concentration index presented by Eq. (1) minus the estimated contributions of the need variables calculated in Eq. (4). When the horizontal index (HI) is positive, the use of services by individuals with a higher socioeconomic status is more than their need, and when it is negative it indicates that the poor people of the community have received services more than their need [25]. The reference groups employed in the analysis were single, women, under the age of 30 , who had college and above education, were in the highest socioeconomic quintile and had basic and complementary insurance. All analyses were performed on rural and non-rural separately.

\section{Results}

Table 1 shows the characteristics of the participants. The $\mathrm{C}$ for inpatient services were negative in both rural $(C=-0.079)$ and non-rural areas $(C=-0.096)$ pointing toward a higher utilization among individuals belonging to lower income households. On the other hand, the $\mathrm{C}$ for outpatient services were positive in both rural $(C=$ $0.038)$ and non-rural $(C=0.007)$, which indicated concentration of these services in higher socioeconomic groups. The concentration curves in Fig. 1, confirmed what was indicated by the Concentration indexes.

After controlling for need factors, the HI was positive and significant for outpatient services in rural $(\mathrm{HI}=$ $0.039)$ and non-rural areas $(\mathrm{HI}=0.008)$, indicating that for given need, the better off make greater use of outpatient services. The HI remained negative for inpatient services in rural $(\mathrm{HI}=-0.068)$ and non-rural areas $(\mathrm{HI}=-0.090)$, which was significant only in non- 
Table 1 Variable characteristics

\begin{tabular}{|c|c|c|}
\hline Characteristic & Non-rural (\%) & Rural (\%) \\
\hline \multicolumn{3}{|l|}{ Sex } \\
\hline Female & $25,904(49.32)$ & $12,753(49.32)$ \\
\hline Male & $26,616(50.68)$ & $13,105(50.68)$ \\
\hline \multicolumn{3}{|l|}{ Education } \\
\hline Uneducated \& Elementary & $25,456(52.61)$ & $17,985(77.20)$ \\
\hline Middle \& High school & $12,830(26.52)$ & $3877(16.64)$ \\
\hline College and above & 10,099(20.87) & 1435(6.16) \\
\hline \multicolumn{3}{|l|}{ Socioeconomic Status (SES) } \\
\hline Poorest SES & $10,818(21.06)$ & $4773(19.59)$ \\
\hline 2th SES & $9587(18.66)$ & $4646(19.07)$ \\
\hline Middle SES & 9960(19.39) & $4492(18.43)$ \\
\hline 4th SES & $10,446(20.33)$ & 4308(17.68) \\
\hline 5th SES & $10,566(20.57)$ & $6150(25.24)$ \\
\hline \multicolumn{3}{|l|}{ Basic insurance } \\
\hline Yes & $46,580(88.69)$ & $24,469(94.63)$ \\
\hline No & $5940(11.31)$ & 1389(5.37) \\
\hline \multicolumn{3}{|l|}{ Supplementary Insurance } \\
\hline Yes & $11,617(24.58)$ & $1736(7.07)$ \\
\hline No & $35,645(75.42)$ & $22,828(92.93)$ \\
\hline \multicolumn{3}{|l|}{ Age } \\
\hline$<30$ & $26,878(51.18)$ & $14,215(54.97)$ \\
\hline $30-59$ & 20,292(38.64) & $8788(33.99)$ \\
\hline$\geq 60$ & $5350(10.19)$ & $2855(11.04)$ \\
\hline \multicolumn{3}{|l|}{ Marital status } \\
\hline Single & $18,455(40.54)$ & $8601(39.85)$ \\
\hline Married & $27,068(59.46)$ & $12,981(60.15)$ \\
\hline \multicolumn{3}{|l|}{ being employed } \\
\hline Yes & $27,163(65.60)$ & $12,188(63.13)$ \\
\hline No & $14,241(34.40)$ & $7118(36.87)$ \\
\hline \multicolumn{3}{|l|}{ Health status } \\
\hline Good & $46,690(88.90)$ & $22,875(88.46)$ \\
\hline Poor & $5830(11.10)$ & 2983(11.54) \\
\hline \multicolumn{3}{|l|}{ Outpatient utilization } \\
\hline Yes & $8743(16.65)$ & $4441(17.17)$ \\
\hline No & $43,777(83.35)$ & $21,417(82.83)$ \\
\hline \multicolumn{3}{|l|}{ Inpatient utilization } \\
\hline Yes & $3582(6.82)$ & $1181(7.00)$ \\
\hline No & 48,938(93.18) & $24,047(93.00)$ \\
\hline
\end{tabular}

rural area indicating that the inpatient services were more utilized by the poor groups (Table 2).

Table 2 (inpatient services) and Table 3 (outpatient services) show the results of the decomposition analysis by non-rural and rural areas. The first column, regression coefficients show the partial effect of each variable on the utilization. The second column indicates the elasticity of health care utilization for each determinant. The third column shows the concentration index of each of the determinants included in the analysis. The two last columns show the absolute and percentage contributions of each factors to the overall concentration index.

Regarding the utilization of inpatient care, there was a significant positive association between utilization of services and older age, poor health and low SES in rural residents. In non-rural area, being married, unemployed and individuals who reported poor health, were more likely to use services. Male, people in middle age (3059) and poor health status were all concentrated among the poor individuals. Need factors explained a smaller proportion of the inequality favoring the poor in both rural and non-rural areas (13.83 and 5.84\% respectively), while non-need factor accounted for bigger proportion of the inequality (57.024 and $39.83 \%$ in rural and nonrural areas, respectively). Among the need factors, poor health was the major contributor, whereas the other factors displayed an insubstantial role. Among the nonneed factors, lack of supplementary insurance and low SES made the largest contributions to explain the propoor inequalities in both rural and non-rural areas.

For the utilization of outpatient care, in rural areas, there was a negative association between older age, sex, marital status and lack of basic insurance and a positive association between high SES, poor health, being unemployed and lack supplementary insurance with use of this service. On the other hand, in non-rural areas, individuals with poor health, high SES and lacking supplementary insurance were more likely to use the services. The need factors were slightly offsetting $(-2.26 \%$ and $16.30 \%$ in rural and non-rural, respectively) the contribution of non-need factors which in this case accounted for most of the inequality favoring the better-off (92.96 and $46.99 \%$ in rural and non-rural, respectively). The lack of supplementary insurance coverage was the largest non-need contributor in both rural and non-rural area, with an additional contribution coming from education. Interestingly, high SES made a very small contribution to the pro-rich inequalities in rural area while low SES was instead offsetting the inequalities in non-rural area.

\section{Discussion}

The results of this study suggest firstly, that whereas inpatient services are fairly equitable and seem to meet the principle of horizontal equity, the use of outpatient services is substantially concentrated among the well-off population. Second, that rural areas displayed lower levels of inequality in the use of inpatient services while non-rural areas showed lower levels of inequalities in the use of outpatient services. Third, the decomposition analysis suggested that non-need factors were the most 

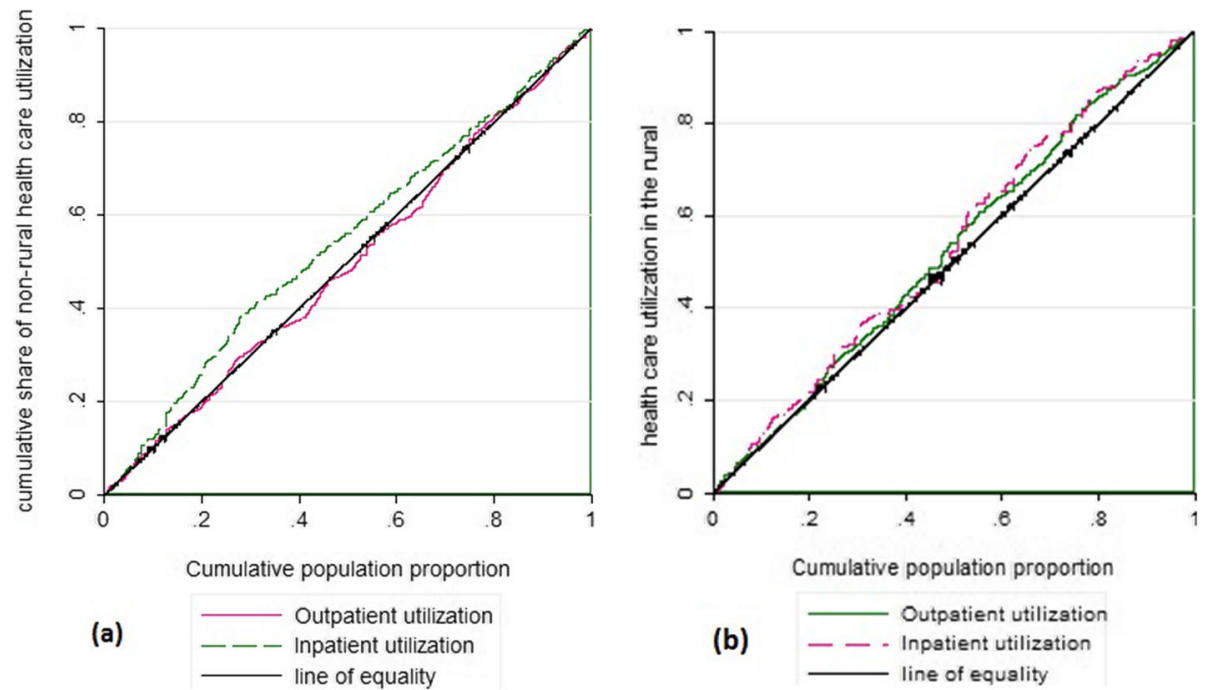

Fig. 1 Concentration curve for outpatient and inpatient health care utilization in rural and non-rural

important contributors to explain both inpatient and outpatient inequalities, and among them, the lack of supplementary insurance and SES were the most important explanatory factors.

The overall observed pattern of inequality in outpatient and inpatient healthcare services in our study is in accordance with the findings of studies conducted in three high-income countries in East Asia (Honk Kong, South Korea, and Taiwan) [26] and Brazil [27]. On the one hand, private insurance coverage (Hong Kong and Brazil), low education, unemployment (South Korea), place of residency and income (Taiwan) were the main explanatory factors for outpatient pro-rich inequalities. On the other hand, policy interventions as for example services-onwheel and exemption of co-payment in rural residents were driving the pro-poor inpatients inequalities [26, 27]. Contrasting patterns to those found in the present study have also been described in other settings. For example a study in China reported pro-rich inequity of inpatient utilization in rural residents [28]. Our study adds to this meagre literature by suggesting the levels of inequalities in the use of inpatient services among rural residents is lower than in the non-rural ones. Possible explanations of our findings could be the successful implementation of the family physician program, the rural insurance scheme and the referral system, which have already shown increased equal and comfortable access to health services $[11,29]$. As a result of these interventions, family physicians act as a gatekeeper to the system and rural insurance holders only pay a small portion of the total costs when they are admitted to hospitals through the referral system. Conversely, in large cities, family physicians doesn't have an obvious role as gate-keepers [30].

This study also suggested that utilization of outpatient service is not equitable among Iranian population. In our study, the pro-rich inequality in outpatient services was higher in rural than in non-rural areas. This inequality was mainly explained by the higher level of utilization among people with no supplementary health insurance, which was in fact concentrated among the high SES. In Iran, there are three type of health care services including; public sectors, quasi-public sectors and private sectors. While hospitalization services are mainly provided by the public sector (more than $70 \%$ of inpatient facilities and services), more than $70 \%$ of outpatient facilities and services are provided by the private sector [31]. Private sector fee is much higher than the public sector's, which therefore could lead to pro-rich outpatient services. Despite increasing the share of government and insurance funds in total health expenditures, finding has shown the out of pocket payments of the households increased even more than the previous years [15]. After the implementation of the Health transformation Plan, private sector services fee increased by an average of over $100 \%$ [32]. In addition, part of the outpatient service including dental services and rehabilitation services are not covered by insurance and have also been reported to be pro-rich [31, 33]. Despite the high insurance coverage in Iran, service coverage and cost coverage by insurances are not sufficient when an individual need to use the private sector, which consequently has led to reduced access and utilization of services among the low-income individuals [34]. Also 
Table 2 Decomposition of Concentration Index for Inpatient health care utilization in rural and non-rural

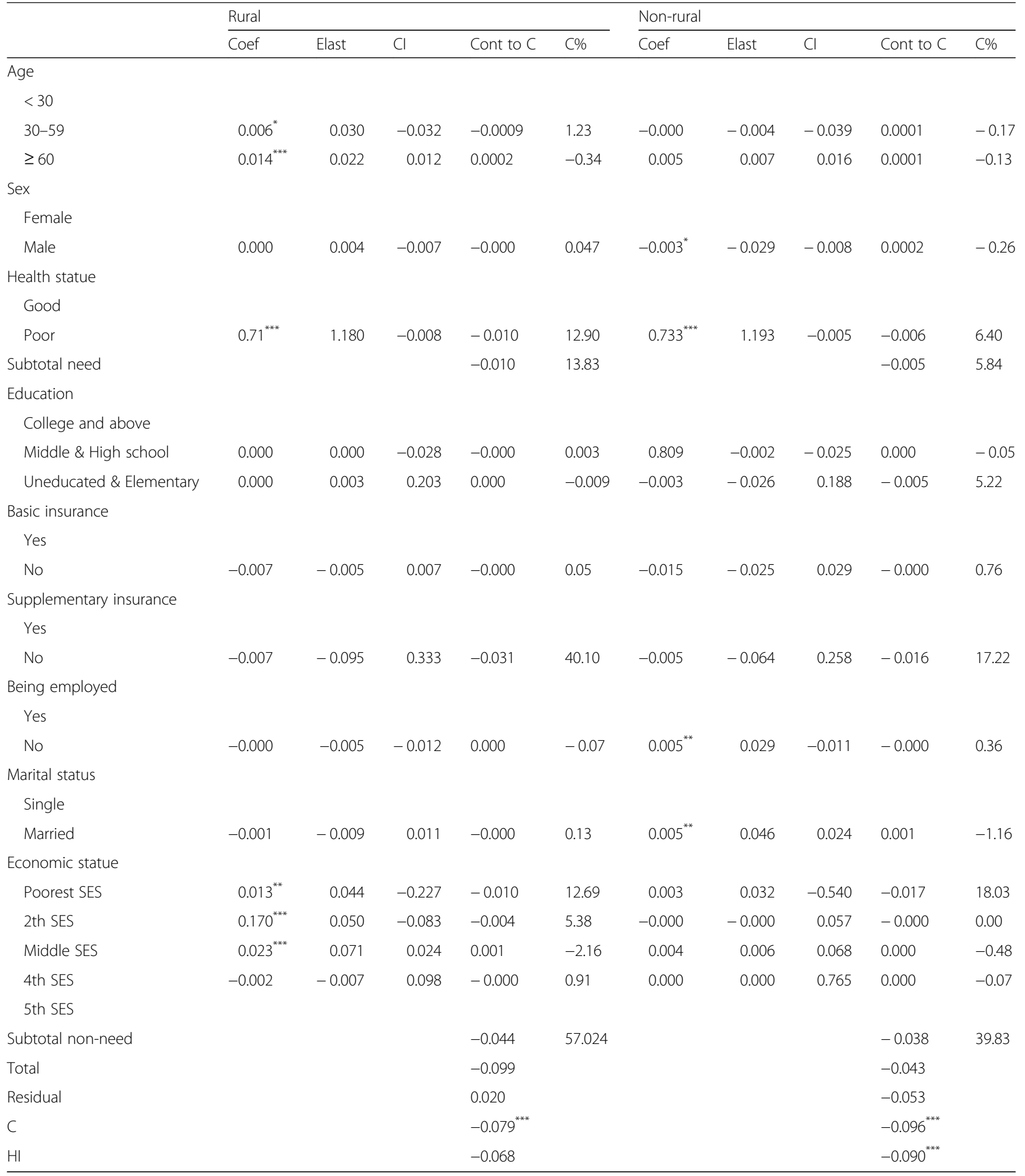

Coeff Marginal effects, Elast elasticity, $\mathrm{Cl}$ Concentration index of the social determinants, Cont to C Contribution to the overall concentration index, C\% unadjusted percentage calculated on the overall explained portion of the $\mathrm{C}$, HI Horizontal Index

${ }^{*} 0.01 \leq p<0.05 ; * * 0.001 \leq p<0.01 ;{ }^{* * *} p<0.001$

evidence of other studies in Iran have shown that low quality of health care delivery by public sectors and family physicians led to seeking care in private sectors and specialist services particularly in outpatient care [35, 36]. Similar to our findings, a previous study in Iran showed that poor socioeconomic status was associated with low 
Table 3 Decomposition of Concentration Index for Outpatient health care utilization in rural and non-rural

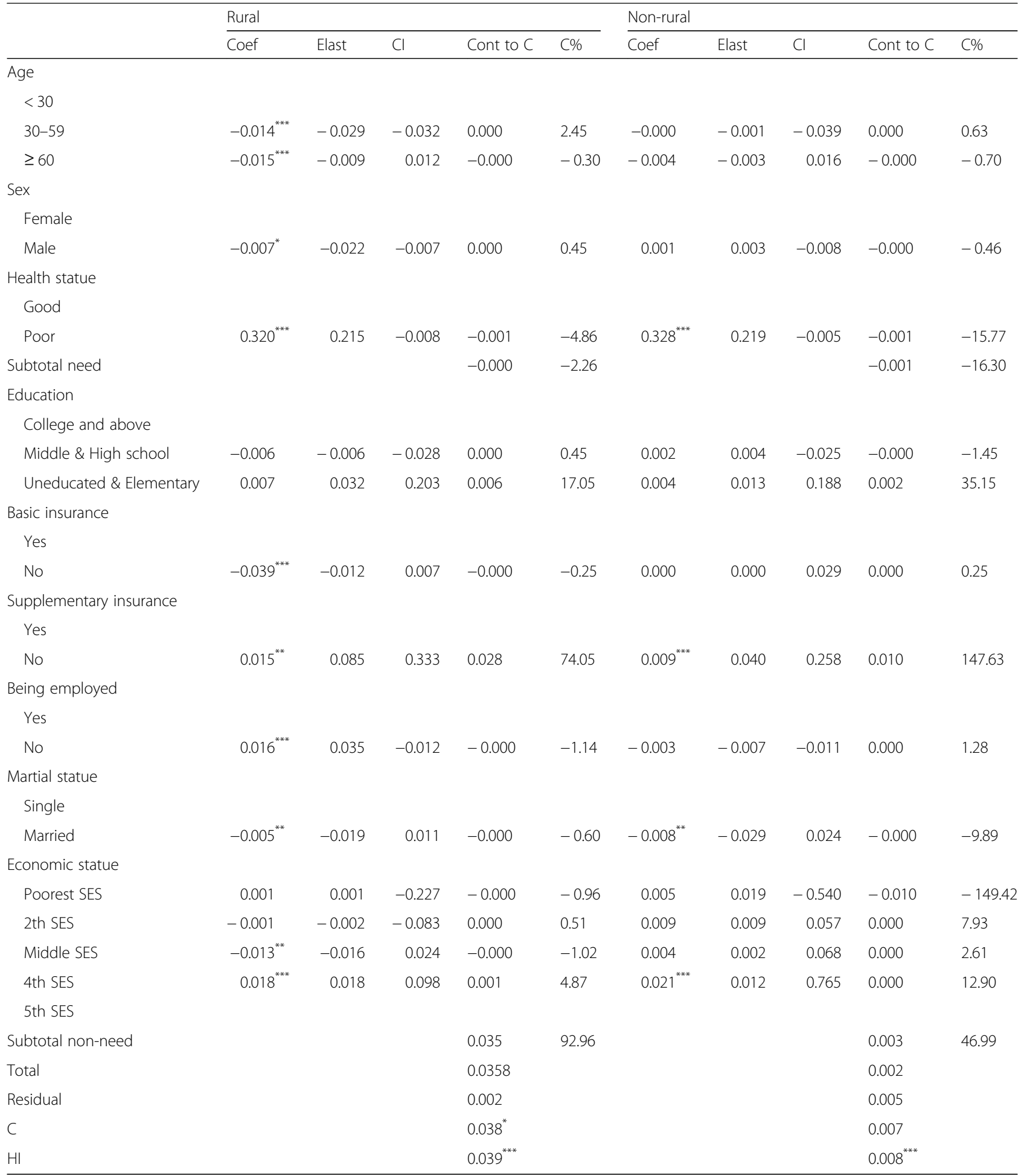

Coeff Marginal effects, Elast elasticity, $\mathrm{Cl}$ Concentration index of the social determinants, Cont to C Contribution to the overall concentration index, C\% unadjusted percentage calculated on the overall explained portion of the C, HI Horizontal Index

${ }^{*} 0.01 \leq p<0.05 ; * * 0.001 \leq p<0.01 ;{ }^{* * *} p<0.001$

utilization of services [37]. In contrast of our study and other studies in Iran, a local study conducted in 2012 in Shiraz (the fifth most populous city of Iran) reported a pro-poor inequality in utilization of outpatient services after standardizing for need factors. The allocation of subsidies and low cost of services in the public sector, 
high insurance coverage, and financial barriers related to upper level access, reported as the main factors associated to the pro-poor inequality; in addition the reason reported for under-utilization of the rich individuals is low quality of services in Shiraz [38].

This study has some limitations; the data on socioeconomic status, health status, and the utilization of services were collected via self-reported questionnaire, as a result, the collected data might have some bias. In the present study a PCA analysis was used to calculate socioeconomic variable therefore the choice of variables and the appropriateness of the weights assigned to them might be amatter of concern [4]. In addition, the selfreported health variable was binary (good and poor health), which will not indicate variation in health status and might not adequately discriminate those in need for health care services, therefore its effect may be overestimated or underestimated. Another limitation is big residuals in some of the models meaning the variables included in the model were not able to adequately explain the inequalities in the outcome. Some other variables i.e. quality of health care delivery could have been relevant to explain these inequalities, however information was not available in the dataset. Also to handle the limitation of secondary data, survey method including the survey instrument was considered. Concerning the analysis, we used the correction proposed by Wagstaff et al. to the concentration index because of the binary nature of the health outcome [4].

\section{Conclusions}

Our results, suggest a pro-poor income-related inequality in inpatient and pro-rich income-related inequality in outpatient services. Inequalities are mainly explained by non-need factors i.e. lack of supplementary insurance and SES. Magnitude of HI was greater in rural areas for outpatient services and greater in non-rural area for inpatient services. Disentangle the different contribution of determinants as well as variations in $\mathrm{HI}$ among rural and non-rural areas provide helpful information for decision makers to re-design policy and re-distribute resource allocation in order to reduce the socioeconomic gradient in health care utilization.

\section{Abbreviations \\ C: Concentration Index; CC: Concentration Curve; HI: Horizontal Inequity index; UHC: Universal health coverage; PHC: Public health care; UHS: Utilization of Health Services; PCA: Principal component analysis}

\section{Acknowledgements}

This project was supported and registered by Kurdistan University Medical Science in Iran.

\section{Authors' contributions}

FM and GM contributed to the conceptualizing, planning and writing the article, statistical analysis, result interpretation, literature review. PM, contributed to the result interpretation, literature review. BP and RM contributed to literature review. All authors read and approved the final manuscript.

\section{Funding}

The authors received no specific funding for publishing, or preparation of the manuscript of this work.

Availability of data and materials

The datasets used and/or analyzed during the current study are available from the corresponding author on reasonable request.

\section{Ethics approval and consent to participate}

This study was conducted according to the guidelines laid down in the Declaration of Helsinki and all procedures involving human subjects were approved by the Kurdistan University of Medical Sciences Ethics Committee (with IR.MUK.REC.1395/396 the committee's reference number).

\section{Consent for publication}

Not applicable.

\section{Competing interests}

The authors declare that they have no conflict of interest.

\section{Author details}

${ }^{1}$ Social Determinants of Health Research Center, Kurdistan University of Medical Sciences, Sanandaj, Iran. ${ }^{2}$ Department of Public Health and Clinical Medicine, Epidemiology and Global Health, Umeå University, Umeå, Sweden. ${ }^{3}$ School of Public Health and Institute of Public Health Research, Epidemiology and Biostatistics, Tehran University of Medical Sciences, Tehran, Iran. ${ }^{4}$ Department of Epidemiology and Biostatistics, Kurdistan University of Medical Sciences, Pasdaran Ave, Sanandaj, Iran.

Received: 7 October 2019 Accepted: 8 June 2020

Published online: 12 June 2020

\section{References}

1. Boerma T, Eozenou P, Evans D, Evans T, Kieny M-P, Wagstaff A. Monitoring progress towards universal health coverage at country and global levels. PLoS Med. 2014;11(9):e1001731.

2. Carrin G, James C, Organization WH. Reaching universal coverage via social health insurance: key design features in the transition period; 2004.

3. Atun R, Aydın S, Chakraborty S, Sümer S, Aran M, Gürol I, et al. Universal health coverage in Turkey: enhancement of equity. Lancet. 2013;382(9886): 65-99.

4. O'Donnell OA, Wagstaff A. Analyzing health equity using household survey data: a guide to techniques and their implementation: World Bank publications; 2008

5. Culyer AJ, Wagstaff A. Equity and equality in health and health care. J Health Econ. 1993;12(4):431-57.

6. Ev D, Koolman $X$, Jones AM. Explaining incomeâ€ related inequalities in doctor utilisation in Europe. Health Econ. 2004;13(7):629-47.

7. Fendall N. Declaration of Alma-Ata. Lancet. 1978;312(8103):1308

8. Bonilla-Chacín ME, Aguilera N. The Mexican social protection system in health; 2013.

9. Takian A, Rashidian A, Kabir MJ. Expediency and coincidence in reengineering a health system: an interpretive approach to formation of family medicine in Iran. Health Policy Plan. 2010;26(2):163-73.

10. Ibrahimipour H, Maleki M-R, Brown R, Gohari M, Karimi I, Dehnavieh R. A qualitative study of the difficulties in reaching sustainable universal health insurance coverage in Iran. Health Policy Plan. 2011;26(6):485-95.

11. Kalhor R, Azmal M, Kiaei MZ, Eslamian M, Tabatabaee SS, Jafari M. Situational analysis of human resources in family physician program: survey from Iran. Materia socio-Med. 2014:26(3):195.

12. Takian A, Rashidian A, Doshmangir L. The experience of purchaser-provider split in the implementation of family physician and rural health insurance in Iran: an institutional approach. Health Policy Plan. 2015;30(10):1261-71.

13. Takian A, Doshmangir L, Rashidian A. Implementing family physician programme in rural Iran: exploring the role of an existing primary health care network. Fam Pract. 2013;30(5):551-9.

14. Doshmangir L, Rashidian A, Ravaghi H, Takian A, Jafari M. The experience of implementing the board of trustees' policy in teaching hospitals in Iran: an 
example of health system decentralization. Int J Health Policy Manag. 2015;4(4):207.

15. Yazdi-Feyzabadi V, Bahrampour M, Rashidian A, Haghdoost A-A, Javar MA, Mehrolhassani $\mathrm{MH}$. Prevalence and intensity of catastrophic health care expenditures in Iran from 2008 to 2015: a study on Iranian household income and expenditure survey. Int J Equity Health. 2018;17(1):44.

16. Ehsani-Chimeh E, Sajadi HS, Majdzadeh R. Iran towards universal health coverage: the role of human resources for health. Med I Islamic Repub Iran (MJIRI). 2018;32(1):578-82.

17. Mohammadbeigi A, Hassanzadeh J, Eshrati B, Rezaianzadeh A. Decomposition of inequity determinants of healthcare utilization, Iran. Public Health. 2013;127(7):661-7.

18. Pourreza A, Khabiri R, Rahimi Foroushani A, Akbari Sari A, Arab M, Kavosi Z. Health care-seeking behavior in Tehran, Islamic Republic of Iran. World Appl Sci J. 2011:14(8):1190-7.

19. Etemad K, Yavari P, Mehrabi Y, Haghdoost A, Motlagh ME, Kabir MJ, et al. Inequality in utilization of in-patients health services in Iran. Int J Prev Med. 2015;6:45.

20. Abouie A, Majdzadeh R, Khabiri R, Hamedi-Shahraki S, Emami Razavi SH, Yekaninejad MS. Socioeconomic inequities in health services' utilization following the health transformation plan initiative in Iran. Health Policy Plan. 2018;33(10):1065

21. Moradi G, Mostafavi F, Azadi N, Esmaeilnasab N, Ghaderi E. Socioeconomic inequality in childhood obesity. J Res Health Sci. 2017;17:3.

22. Wagstaff A, O'Donnell O, Van Doorslaer E, Lindelow M. Analyzing health equity using household survey data: a guide to techniques and their implementation: World Bank publications; 2007.

23. Wagstaff $A$. The bounds of the concentration index when the variable of interest is binary, with an application to immunization inequality. Health Econ. 2005;14(4):429-32.

24. Mosquera PA, Waenerlund A-K, Goicolea I, Gustafsson PE. Equitable health services for the young? A decomposition of income-related inequalities in young adults' utilization of health care in northern Sweden. Int J Equity Health. 2017;16(1):20.

25. Van Doorslaer E, Wagstaff A, Van der Burg H, Christiansen T, De Graeve D, Duchesne I, et al. Equity in the delivery of health care in Europe and the US. J Health Econ. 2000;19(5):553-83.

26. Jui-fen RL, Leung GM, Kwon S, Tin KY, Van Doorslaer E, O'Donnell O. Horizontal equity in health care utilization evidence from three high-income Asian economies. Soc Sci Med. 2007:64(1):199-212.

27. Macinko J, Lima-Costa MF. Horizontal equity in health care utilization in Brazil, 1998-2008. Int J Equity Health. 2012;11(1):33.

28. Zhou Z, Gao J, Fox A, Rao K, Xu K, Xu L, et al. Measuring the equity of inpatient utilization in Chinese rural areas. BMC Health Serv Res. 2011;11(1):201.

29. Khayyati F, Motlagh ME, Kabir M, Kazemeini $\mathrm{H}$. The role of family physician in case finding, referral, and insurance coverage in the rural areas. Iran J Public Health. 2011:40(3):136.

30. Takian A. Implementing family medicine in Iran identification of facilitators and obstacles: London School of Hygiene \& tropical medicine; 2009.

31. Rezaei S, Hajizadeh M, Bazyar M, Kazemi Karyani A, Jahani B, Karami MB. The impact of health sector evolution plan on the performance of hospitals in Iran: evidence from the Pabon lasso model. Int J Health Governance. 2018; 23(2):111-9.

32. Moghadam TZ, Raeissi P, Jafari-Sirizi M. Analysis of the health sector evolution plan from the perspective of equity in healthcare financing: a multiple streams model. Int J Human Rights Healthc. 2018. https://doi.org/ 10.1108/JHHRH-07-2018-0044.

33. Karami Matin B, Hajizadeh M, Najafi F, Homaie Rad E, Piroozi B, Rezaei S. The impact of health sector evolution plan on hospitalization and cesarean section rates in Iran: an interrupted time series analysis. Int J Qual Health Care. 2017;30(1):75-9.

34. Rashidian A, Joudaki H, Khodayari-Moez E, Omranikhoo H, Geraili B, Arab M. The impact of rural health system reform on hospitalization rates in the Islamic Republic of Iran: an interrupted time series. Bull World Health Organ. 2013;91:942-9.

35. Dehnavieh R, Kalantari AR, Sirizi MJ. Urban family physician plan in Iran: challenges of implementation in Kerman. Med J Islam Repub Iran. 2015;29:303.

36. LeBaron SW, Schultz SH. Family medicine in Iran: the birth of a new specialty. Fam Med-Kansas City. 2005;37(7):502.
37. Piroozi B, Moradi G, Nouri B, Bolbanabad AM, Safari H. Catastrophic health expenditure after the implementation of health sector evolution plan: a case study in the west of Iran. Int J Health Policy Manag. 2016;5(7):417.

38. Kavosi Z, Mohammadbeigi A, Ramezani-Doroh V, Hatam N, Jafari A, Firoozjahantighi A. Horizontal inequity in access to outpatient services among Shiraz City residents, Iran. J Res Health Sci. 2015;15(1):37-41.

\section{Publisher's Note}

Springer Nature remains neutral with regard to jurisdictional claims in published maps and institutional affiliations.

\section{Ready to submit your research? Choose BMC and benefit from:}

- fast, convenient online submission

- thorough peer review by experienced researchers in your field

- rapid publication on acceptance

- support for research data, including large and complex data types

- gold Open Access which fosters wider collaboration and increased citations

- maximum visibility for your research: over $100 \mathrm{M}$ website views per year

At BMC, research is always in progress.

Learn more biomedcentral.com/submissions 